\title{
CORRESPONDENCE
}

\section{$\not \varnothing$}

Corresponden:s are asked to be briet

Danger of Saline Emetics in First-aid for Poisoning

C. J. C. Roberts, M.R.C.P., and M. J. Noakes, M.B. .................683

Safety and Fibreoptic Bronchoscopy P. Hugh-Jones, F.R.C.P... . . . . . . .683

Place of Diagnostic Radiology in Medicine

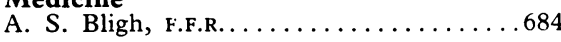

Dangers of Oxytocin-induced Labour to

Fetuses

Complications of Carbenoxolone

Therapy

I. D. Heath, M.R.C.P.; D. O. Gibbons,

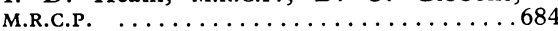

Beta-adrenergic Blocking Agents in

Patients with Renal Failure

D. J. Warren, M.R.C.P., and others... . . 685

Malabsorption in Overland Travellers to

India M. Tomkins, M.R.C.P., and W. P.

A. M. Tomkins, M.R.C.P., and W. P. 685

Wartime Penicillin

Sir Ian Fraser, F.R.c.s. . . . . . . . . . . . 685
Tapeworms and Isolation

F. J. Wright, F.R.C.P.

Hypertension and Myocardial Infarcti

D. M. D. Lambert, M.R.C.G.P.........685

Chickenpox from Herpes Zoster

P. J. Wilkinson, M.B., and others . . . . . . 686

Alkaline Phosphatase Levels in Epileptic Subjects

D. J. F. Rowe, PH.D. . . . . . . . . . 686

Larrey and Debridement

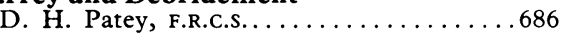

Infections in Asplenic Adults

E. Ask-Upmark, M.D. . . . . . . . . . . . . .6687

Amitriptyline Poisoning in Childhood T. L. Chambers, M.R.C.P., D.C.H., and A. D. Kindley, M.B. .................668

Lawn Mower Injuries

R. G. Thompson, M.R.c.s., and I. A. Harper, M.R.C.PATH. ..................687

Alliterative Anxiety about Arsenic

S. K. Goolamali, M.R.C.P... . . . . . . . . 687

Pontomedullary Listeriosis in Renal

Allograft Recipient

A. G. Samuel-Gibbun, B.M., and others. . . 687
TSH Level and Thyroid Function

G. Antony, M.D..................688

Myeloblastic Transformation

B. T. Colvin, M.R.C.P., and others . . . . . 688

Screening for Rickets

S. A. Haider, M.R.C.P.GLAS. . . . . . . . . 688

Treatment of C.N.S. Involvement in

Systemic Lupus Erythematosis

Y. Levo, M.D... . . . . . . . . . . . . . . . . . 689

Disruption of the Family

L. C. Hurst, M.R.C.PSYCH. . . . . . . . . . 689

B-Lymphocytes as Target Cells for E.B.

Virus Transformation
F. Mizuno, and others ............669

Emergency Bed Service

C. D. Walker, M.B.......... . . . . 689

Meeting the Need for Doctors

T. S-B. Kelly, F.R.C.S., and S. D. V. Weller,

F.R.C.P. $\quad \ldots \ldots \ldots \ldots \ldots \ldots \ldots \ldots \ldots 689$

Doctors' Pay

S. Mehta, F.F.A.R.C.S., and others; A. R.

Rogers, M.B.....................690

G.M.C. By-election

G. N. Jamieson, M.B.; M. M. Hasan, M.B. . 690

\section{Danger of Saline Emetics in First-aid for Poisoning}

SIR,--Your leading article entitled "First-aid for Poisoning" (26 January, p. 130) states that the case for the use of most first-aid methods of inducing vomiting is "scientifically thin." It points out that the effect of taking an emetic made up with two tablespoonfuls of salt in a tumbler of tepid water is unpredictable.

We have recently reported the case of a 26-year-old woman, who died after the administration of an emetic containing $150 \mathrm{~g}$ of sodium chloride (6 dessertspoonfuls) in the first-aid treatment of a relatively minor overdose of an aspirin-containing analgesic. The main features of her illness were severe metabolic acidosis and a cerebral disorder giving rise to generalized myoclonus and repeated convulsions with hyperpyrexia. Others have reported similar cases. ${ }^{3}$ Ward $^{4}$ has warned that saline emetics may precipitate pulmonary oedema. Since our case occurred two further unpublished cases of etc.,

Plymouth General Hospital,

Plymouth coma apparently caused by saline emetics have been brought to our attention.

There is evidence then that the administration of large amounts of salt to induce emesis is accompanied by considerable danger. The danger is enhanced by the widely held belief that this common household remedy is completely safe regardless of dosage. We would recommend that first-aid bocks which carry recipes for salt emetics should also warn against overdose.-We are,

Roberts, C. J. C., and Noakes, M. J., Postgraduate Medical fournal, 1974, 50, 513

Laurence, B. H., and Hopkins, B. E., Medical Fournal of Australia, 1969, 1, 1301 .

Roberstson, W. Q., Fournal of Pediatrics, 1971,

79, 877.
Ward, D. J., British Medical fournal, 1963, 2,

\section{Safety and Fibreoptic Bronchoscopy}

SIR,-A leading article which may help to increase the safety of any diagnostic procedure is indeed welcome. Unfortunately, it seems to me that your leading article (31 August, p. 542) on fibreoptic bronchoscopy omits important information and is consequently misleading.

It rightly implies in the first paragraph that Dr. Ikeda's introduction of the flexible instrument in $1968^{1}$ opened up new horizons for the endoscopist; and for the chest physician or surgeon there is at last chance of diagnosing much more lung cancer at a curable stage. So it is important no to suggest that it is a dangerous procedure unless that is a fact.

A point not mentioned in your article is that it is imperative to have adequate experience in the use of a rigid bronchoscope before using a flexible instrument. The latter has not replaced rigid bronchoscopy. The first step, both diagnostically and for safety, is to decide which instrument to use on which patient or whether to combine them, and by what route the flexible instrument, if used, shall be introduced. A flexible bronchoscope can be passed through the nose, the mouth, a rigid bronchoscope, an endotracheal tube, or a tracheostomy tube, and either local or general anaesthesia can be used with any of these routes.

The transnasal route requires a minimum of topical anaesthesia if a suitable intranasal tube is used. I found no difficulty in inserting a flexible bronchoscope into my own trachea, seeing my own carina, and then talking in a Donald Duck sort of way. It is the ideal route for outpatients and bedside bronchoscopy and satisfactory in about $80 \%$ of patients-the rest either have too narrow nasal airways or too sharp a bend in their nose for it to be comfortable or even practicable. Your article mentions neither the technique of Smiddy et al. ${ }^{2}$ nor that of Marvin Sackner and his co-workers. ${ }^{3}$ These last are important references.

But for prolonged search and careful inspection of the tree to third or fourth generation bronchi and taking scrapings, brushings, and biopsy in the search for early cancer the flexible instrument is best passed through a cuffed endotracheal tube with an attachment at the proximal end giving a $\mathrm{T}$-junction for ventilating the patient and a diaphragm with a central hole in it to support the fibreoptic bronchoscope in the centre of the airway. I learnt this technique from the practice used in the Mayo Clinic-Johns Hopkins programme for the early diagnosis of lung cancer. ${ }^{5}$ This technique is to safety in fibreoptic work through an endotracheal tube what the Hart technique is to rigid bronchoscopy. ${ }^{6}$ It is remarkable to me that this work, perhaps the most extensive in the U.S.A., is not even mentioned in your article. I have used this technique, ${ }^{7}$ slightly modified, since I visited Dr. Marsh at the Johns Hopkins Hospital. Our concurrent mass spectrometer sampling of expired gases 